\title{
GEODIVERSIDADE NO CEMITÉRIO MUNICIPAL DE CURITIBA COMO ELEMENTO CULTURAL EM ANÁLISES DE PATRIMÔNIO
}

\author{
Antonio Liccardo \& Clarissa Grassi \\ Departamento de Geociências da Universidade Estadual de Ponta Grossa. Av. Carlos Cavalcanti, 4748, Uvaranas, Ponta Grossa, Paraná, \\ CEP 84030-900 - aliccardo@uepg.br; clarissa.grassi@gmail.com
}

\begin{abstract}
RESUMO: Geodiversidade é uma nova abordagem ambiental que vem sendo utilizada na compreensão das relações entre homem e território e refere-se aos elementos abióticos que compõem o meio ambiente. Rochas são a expressão mais evidente dessa geodiversidade e seu aproveitamento como material nobre em arquitetura e engenharia civil remonta às primeiras construções humanas. São um reflexo da geodiversidade disponível numa região e imprimem nos cenários construídos uma característica particular de identidade cultural. Cemitérios são um universo que possibilita o entendimento do mundo dos vivos ao longo das diferentes épocas em que foi utilizado e o Cemitério Municipal de Curitiba é o mais antigo do município, recebendo visitação de pesquisadores e interessados nos aspectos arquitetônicos, históricos, artísticos e sociológicos. Esta proposta apresenta a geodiversidade deste cemitério como uma leitura sobre a evolução no uso de materiais líticos pela sociedade curitibana. As rochas registradas são mármores importados e nacionais, granitos do Paraná e São Paulo, e rochas negras como diabásio e gabro. Outras rochas estão presentes em menor quantidade e apresentam variedade de procedências. A proposição de tombamento deste cemitério como bem cultural vem recebendo aporte de várias pesquisas e, entre elas, este levantamento é um subsídio para este processo.
\end{abstract}

Palavras-chave: CEMITÉRIO, GEODIVERSIDADE, TÚMULOS, CURITIBA

ABSTRACT: GEODIVERSITY IN CURITIBA MUNICIPAL CEMETERY AS CULTURAL ELEMENT IN HERITAGE ANALYSIS. Geodiversity is a new environmental approach that has been used to understanding the relations between man and territory and refers to the abiotic elements that form the environment. Rocks are the most obvious expression of this geodiversity and their use as noble material in architecture and civil engineering dates back to the first human constructions. It's a reflection of geodiversity available in a region and print in the constructed scenarios a particular characteristic of cultural identity. Cemeteries are a universe that allows the understanding of the world of the living along the different periods in which it was used and the Curitiba Municipal Cemetery is the oldest of the city, receiving visiting researchers and those interested in architectural, historical, sociological and artistic features. This proposal introduces geodiversity of this cemetery as an approach on the evolution about uses of lithic materials by Curitiba society. Rocks registered are imported and national marbles, granites from Paraná and São Paulo, and black rocks like diabase and gabbro. Other rocks are present in smaller quantities and variety of sources. The proposition of having this cemetery as cultural object has been receiving funding from various surveys and, among them, this research is a subsidy for this process.

Keywords: CEMETERY, GEODIVERSITY, TOMBSTONES, CURITIBA

\section{INTRODUÇÃO}

No silêncio do campo santo mais antigo de Curitiba, entre múltiplas formas de construções tumulares, elementos arquitetônicos reiteram na cidade dos mortos o papel que seus ocupantes buscaram entre a sociedade dos vivos. Tal qual a cidade de Curitiba, o Cemitério São Francisco de Paula, ou Cemitério Municipal como é conhecido pela população, apresenta uma paisagem visivelmente segmentada em bairros com características que definem períodos e materiais utilizados, assim como delimitam a área ocupada pelas famílias mais abastadas e distintas da sociedade de outrora.

Essa divisão é tão acentuada, que até mesmo os terrenos que abrigam os mausoléus e esculturas importadas, possuem um traçado totalmente diverso do restante do cemitério e encontram-se aglutinados em um espaço visualmente delimitado. É como se antigos bairros nobres, como o Batel, conhecido por ter abrigado as maiores mansões de Curitiba, tivessem sido recriados bem no centro do mapa do cemitério. Os diversos tipos de rocha utilizados na construção ou adorno destes bairros apresentam diferenças marcantes.
Este cemitério vem sendo analisado nos últimos anos com as mais variadas abordagens, considerando o seu papel no registro histórico da cidade e do Estado do Paraná, ou pelos conteúdos artístico, arquitetônico e outros que formam o amálgama cultural. Uma correlação deste conteúdo com a geodiversidade levantada permite a inferência de aspectos relativos à evolução social do município, principalmente pelo uso de certos tipos de rocha e sua maior ou menor disponibilidade ao longo das décadas.

\section{O CEMITÉRIO MUNICIPAL SÃO FRANCISCO DE PAULA}

Criados no Brasil a partir do século XIX, seguindo medidas higienistas já aplicadas aos países europeus, os cemitérios extramuros - que passam a substituir o enterro ad sanctus (dentro das igrejas) desempenham uma espécie de eficácia simbólica da conservação da memória ao materializar monumentos arquitetônicos de jazigos individualizados, em torno dos quais se desenvolvem práticas, cultos e produções de natureza simbólica diversa. É o chamado período áureo da arte tumular, que no Brasil acontece entre 1860 e 1930 (ARIÈS, 2003; VOVELLE, 2004; MOTTA, 2008). 
Campo santo mais antigo de Curitiba, com 157 anos desde sua fundação em 7 de dezembro de 1854 (CAROLLO, 1995), o Cemitério Municipal São Francisco de Paula reúne, entre seus 5.792 túmulos, grande parte dos personagens da história curitibana e paranaense. Entre mausoléus e esculturas muitas vezes importadas da Europa, famílias imprimiram, através da arte tumular, o sentido que a morte passou a adquirir depois do século XIX, a morte "burguesa".

Em seus $51.414 \mathrm{~m}^{2}$, o Cemitério Municipal São Francisco de Paula ocupa um terreno alongado, acomodado ao traço das ruas por formas de trapézio, possuindo uma rua principal cortada por ruelas transversais estreitas (IMAGUIRRE, 1995), que fazem o acesso a todos os jazigos (Figura 1). Para Carollo (1995), no espaço desse cemitério é possível identificar pelo menos quatro "bairros" delimitados pelas diferentes formas de construção dos túmulos. O primeiro, com a predominância de túmulos verticalizados em estelas onde o mármore é o material mais utilizado, compreende a área da entrada principal do cemitério até a localização da antiga capela, demolida na década de 1960 e onde hoje se encontra uma praça.

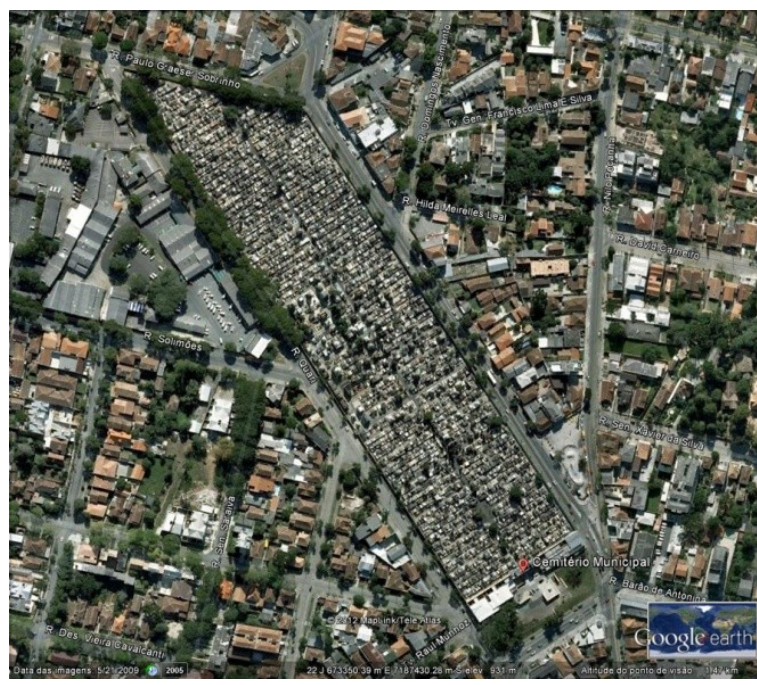

Figura 1 - Planta do Cemitério São Francisco de Paula indicando seu projeto alongado e a distribuição dos túmulos em quadras e ruas. Fonte: Google Earth, 2012

O segundo vem em seguida, formado por capelas e mausoléus cuja característica marcante é a monumentalidade das construções albergadas em terrenos com dimensões maiores. O traçado das quadras é totalmente diferente do padrão geral do cemitério. O terceiro "bairro" está localizado na subida para o cruzeiro, caracterizado pela predominância de jazigos cuja verticalidade é retomada, mas que, ao lugar de estelas funerárias, gavetas se sobrepõem formando um tipo de "predinho", recoberto de materiais como o azulejo. Do cruzeiro para frente, encontra-se o quarto e último bairro, formado por túmulos mais simples, destituídos de estatuária ou maiores elementos decorativos.

A apresentação de um maior número de esculturas executadas em mármore nas primeiras quadras denota a progressão no uso de materiais para a arte tumular e sua relação com a progressão na visão de morte. O mármore marca a construção de túmulos até o final do século XIX e a segunda década do século $X X$, período que coincide com a chegada de marmoristas italianos ao Brasil (LICCARDO, 2010), que difundem ainda mais o uso de adornos e esculturas talhados em mármore (Figura 2).

O bronze, relativamente em pequena quantidade nesse cemitério, acompanha a mudança do uso do mármore para o granito, ocorrido a partir da década de 40 do século XX. Essa mudança na arte tumular acompanha o afastamento que a sociedade do século XX teve para com a temática "morte". Os túmulos suntuosos são deixados de lado e as construções passam a ser cada vez mais livres de adornos e simbologias que remetam às religiões, adotando linhas e ângulos retos (GRASSI, 2006).

Mesmo que muitos túmulos tenham sido reformados ou até demolidos, ainda é possível identificar como o uso de materiais como o mármore e o granito está inserido no traçado do cemitério. Também é possível verificar a influência trazida por imigrantes europeus na construção de seus jazigos. Prova disso é a presença de um único mausoléu em lioz, construído na cidade do Porto, em Portugal e onde está inumada uma família portuguesa (Figura 3). É o caso do imigrante francês, cujo anjo, ainda que tenha sido entalhado em mármore de Carrara, traz a marca de uma marmoraria francesa. A presença do mármore é recorrente nos túmulos de italianos, cuja grande maioria traz esculturas como adornos. Já no caso de imigrantes alemães, prevalece a sobriedade de túmulos de cabeceira, construídos em alvenaria, cuja única peça em mármore é o epitáfio, sempre escrito em alemão gótico (Figura 4). 


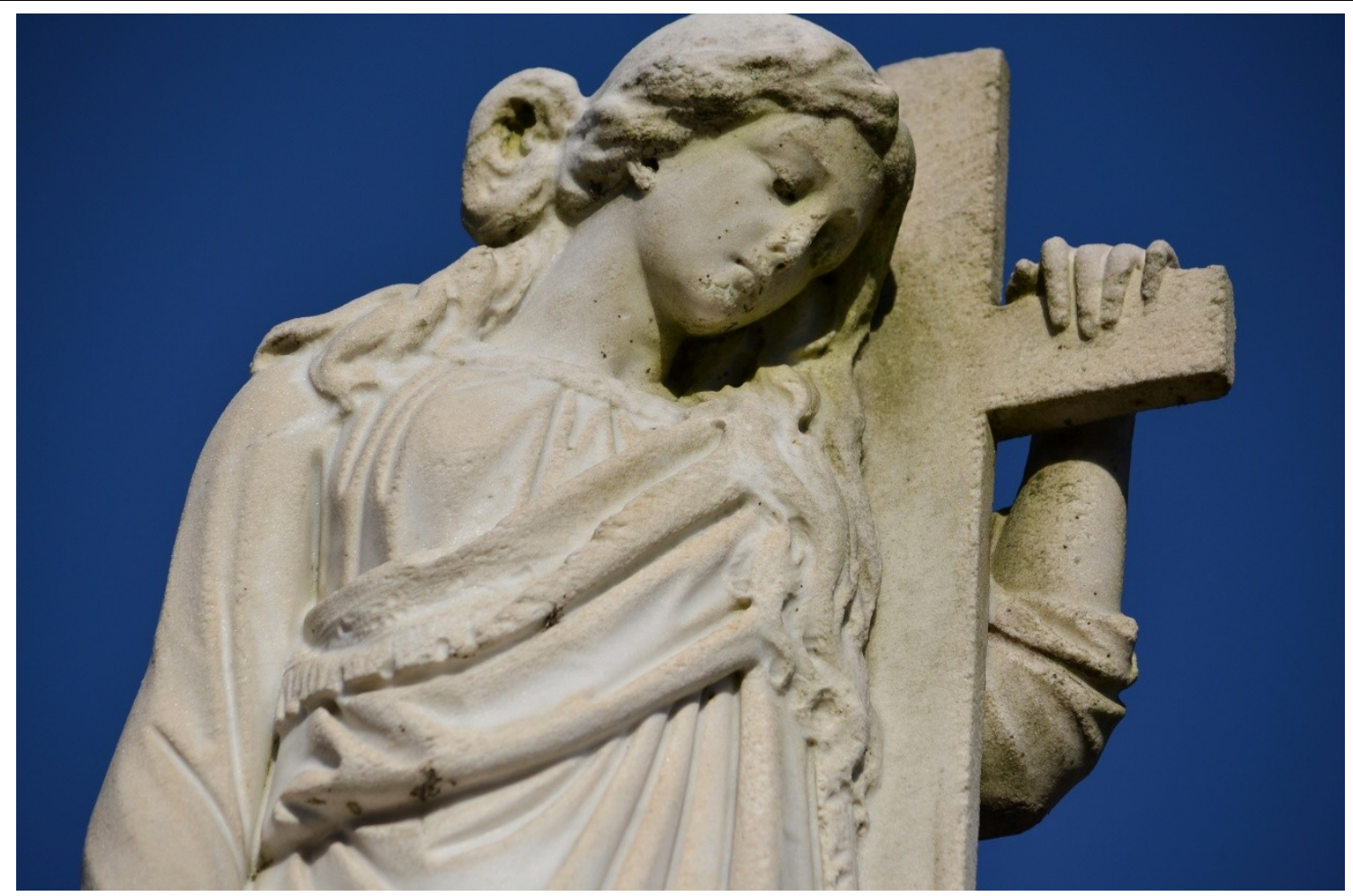

Figura 2 - Escultura de grande conteúdo artístico elaborada em mármore de Carrara com veios acinzentados.

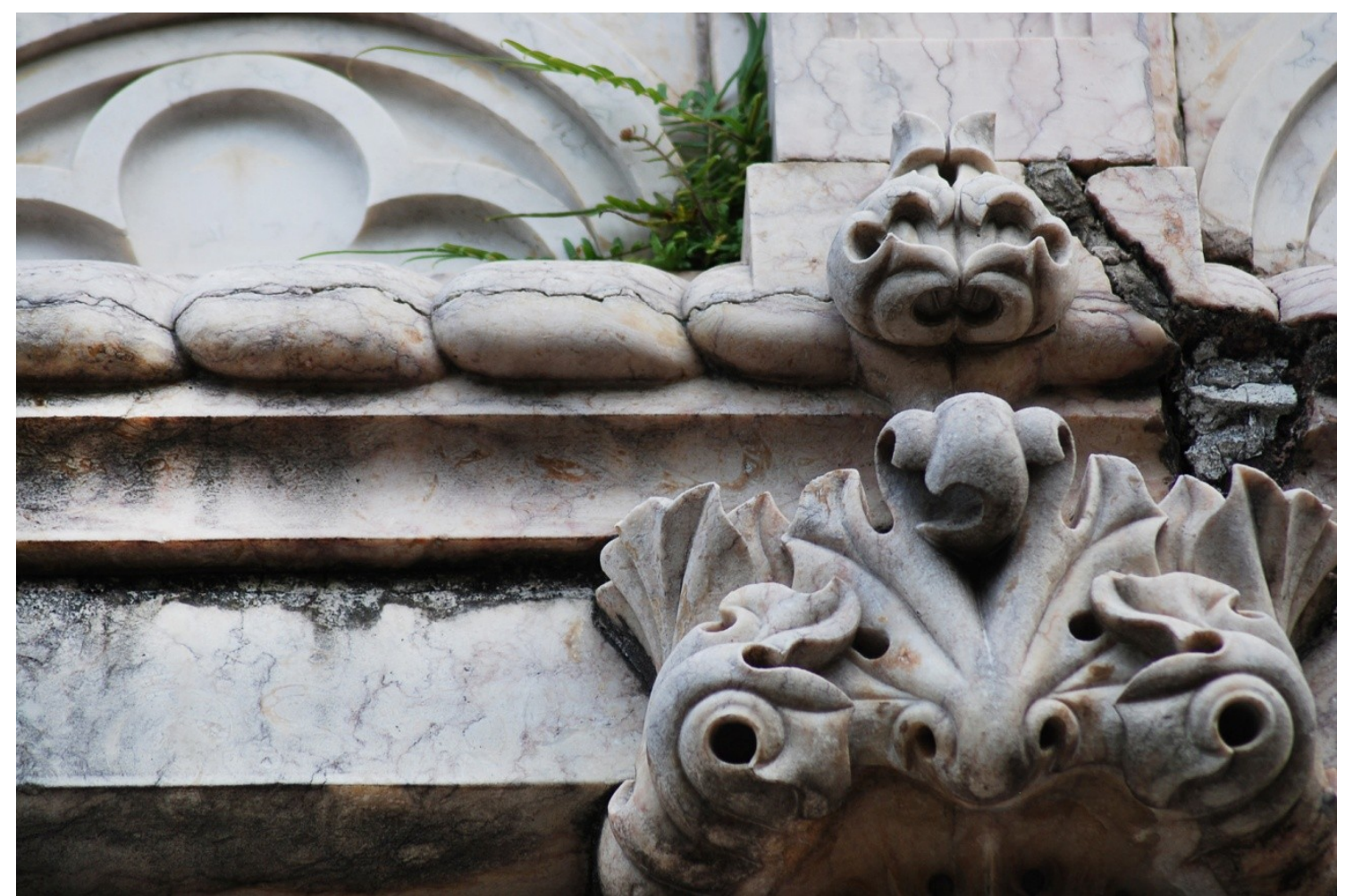

Figura 3 - Detalhe do mausoléu construído em lioz, por canteiro português. 


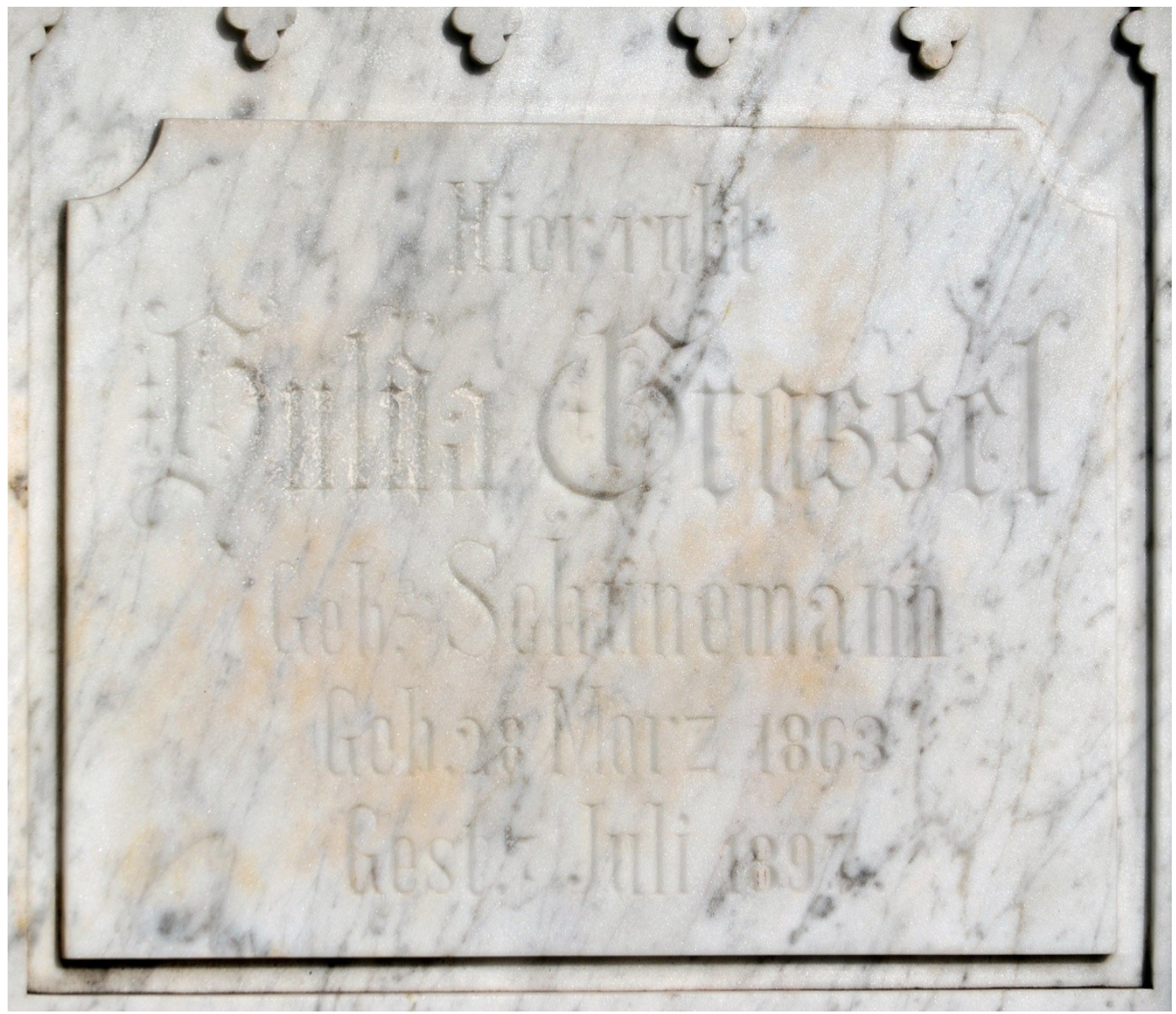

Figura 4-Epitáfio escrito em alemão gótico sobre mármore de Carrara com ornamentações mínimas.

\section{GEODIVERSIDADE E CEMITÉRIOS}

A geodiversidade é um novo enfoque ambiental que vem sendo utilizado na análise das relações entre o homem e o território e refere-se aos elementos abióticos que compõem o meio ambiente e que dão suporte ao desenvolvimento da vida e da biodiversidade. Entre estes componentes estão os minerais e as rochas, rios, montanhas, solos e fósseis, que vêm sendo considerados e, eventualmente, valorizados como patrimônio natural e cultural, conforme diretrizes da UNESCO, nas últimas décadas.

As rochas são a expressão mais evidente dessa geodiversidade e o seu aproveitamento como material nobre em arquitetura e engenharia civil remonta às primeiras construções do ser humano. Atualmente são consideradas ornamentais, ou de revestimento, as rochas que apresentam, além dos aspectos estéticos, algumas qualidades mecânicas para resistir a esforços ou à ação do tempo e são chamadas genericamente de "mármores e granitos". Estas rochas geralmente constituem um reflexo da geodiversidade disponível numa região e imprimem nos cenários construídos uma característica de identidade cultural muito particular.
Um olhar mais detalhado sobre os materiais líticos utilizados nas construções pode revelar não só a composição geológica do lugar, como também importantes aspectos históricos e culturais da sociedade que as construiu. $\mathrm{O}$ uso de mármores, por exemplo, desde os gregos antigos é um exemplo de distinção entre as rochas, assim como o granito entalhado em sarcófagos egípcios que era transportado de longas distâncias por suas características de durabilidade, em sintonia com as crenças religiosas sobre a eternidade.

Os cemitérios como expressão cultural - no sentido antropológico - são um universo que possibilita o entendimento do mundo dos vivos ao longo das diferentes épocas em que foi utilizado. A ideia de apresentar a geodiversidade do cemitério São Francisco de Paula propõe uma discussão sobre a evolução no uso de materiais líticos pela sociedade curitibana, desde 1854, época de seu surgimento, até os dias de hoje, num paralelo com a evolução histórico-social da cidade.

\section{O TURISMO CEMITERIAL}

Para o historiador português Francisco Queiroz (2005), no século XIX os cemitérios foram concebidos quer para os mortos, quer para os vivos. Ou seja, os cemitérios criados no período Romântico 
foram arquitetados para serem visitados e admirados pelas obras de arte neles contidas, obras essas que eram muitas vezes representativas do que de melhor se fazia na época. Com o declínio do romantismo, os cemitérios são deixados de lado e somente retornam à tona nas décadas de 70 e 80 do século $X X$, imbuídos de noções como a herança cultural e de patrimônio.

A exemplo de países que já possuem programas de turismo cemiterial como França (sendo o Cemitério de Père Lachaise o 4 으 ponto turístico mais visitado em Paris), Itália, Espanha, Argentina, Chile e Estados Unidos, o Brasil vem implantando lentamente programas de visitação em seus principais cemitérios, a citar Cemitério da Consolação (em São Paulo), Cemitério São João Batista (no Rio de Janeiro), Cemitério Senhor do Bonfim (em Minas Gerais) e Cemitério da Santa Casa (em Porto Alegre). Trata-se de uma leitura parcial da potencialidade de resgate histórico/cultural que estes campos santos oferecem. A implementação de ações a médio e longo prazo, como visitas guiadas com periodicidade fixa - como vem ocorrendo no Cemitério Senhor do Bonfim, em Belo Horizonte trazem a oportunidade de estruturação de ações mais efetivas com relação à questão da educação patrimonial ligada ao turismo cultural, além de chamar a atenção da população local sobre a necessidade de preservação destes cemitérios.

É nesse sentido que

"[...] o turismo cultural pode ser compreendido como um segmento da atividade turística que, por meio da apreciação, da vivência e da experimentação direta de bens do patrimônio cultural, material e imaterial, e da mediação da comunicação interpretativa, proporciona aos visitantes a participação em um processo ativo de construção de conhecimentos sobre o patrimônio cultural e sobre seu contexto sócio histórico. Em última escala, este processo auxiliará a produção de novos conhecimentos e a conservação dos bens visitados." (COSTA, 2009).

O turismo cultural surge como uma ferramenta que tem potencial para viabilizar a propagação da imagem dos cemitérios como locais repletos de registros e manifestações. Com o suporte de material que oriente os visitantes a compreender melhor a importância histórica, artística e cultural dos cemitérios, assim como a necessidade de sua preservação, poderemos apontar esse tipo de ação também como educação patrimonial. Pois, segundo Oliveira (2011),

" $a$ educação patrimonial pode ser entendida como um processo sistemático e permanente por meio do qual os indivíduos se apropriam dos bens culturais e entendem a necessidade $e$ a importância da valorização e preservação do patrimônio cultural, colocando-se como agentes diretos. Desse processo também decorre $o$ fortalecimento das identidades individuais $e$ coletiva."

Para Poulot (2009),

"ao olhar instruído, o monumento ou as ruínas oferecem o livro aberto da história. Uma espécie de imediatidade da leitura, resultados de longos esforços preliminares culminam em uma história que se absorve pelos olhos."

Nas últimas décadas, as atenções começaram a se voltar para os cemitérios enquanto fonte para estudos, representação da cultura e do passado e locais inspiração artística e visitação turística. As potencialidades de tais locais são múltiplas e podem ser desenvolvidas nas áreas da cultura, patrimônio, história e turismo.

Uma das vertentes de turismo cultural e científico que surgiu na última década é o geoturismo, atividade que vem sendo amplamente incentivada pela UNESCO para áreas de patrimônio natural, e que tem uma tônica de extrair e apresentar informações sobre o meio abiótico. Uma derivação do geoturismo foi o geoturismo urbano que propõe uma forte associação com os processos educativos e de desenvolvimento cultural (LICCARDO et al. 2012).

\section{AS ROCHAS DO CEMITÉRIO MUNICIPAL}

Foram levantados, em 2012, dados sobre detalhes construtivos, lápides, ornamentos e estatuária constituídos de rochas nos 5.792 túmulos, sendo que numa parte expressiva os materiais utilizados são alvenaria e prescindem do uso de rochas como fator estético. Foram considerados apenas os túmulos que apresentaram uma possibilidade de correlação cultural mais expressiva entre outros quesitos (arquitetura, história, conteúdo artístico ou estético) e a representatividade dos materiais líticos (Figura 5).

Como resultado, são apresentadas, de maneira simplificada, as rochas predominantemente encontradas neste campo santo, que são os mármores importados e nacionais, os granitos do Paraná e de São Paulo e as rochas negras como o diabásio e o gabro. Outras rochas estão presentes em muito menor quantidade e apresentam enorme variedade de procedências, algumas, no entanto, merecendo destaque como o lioz, o sienito ou os arenitos. 


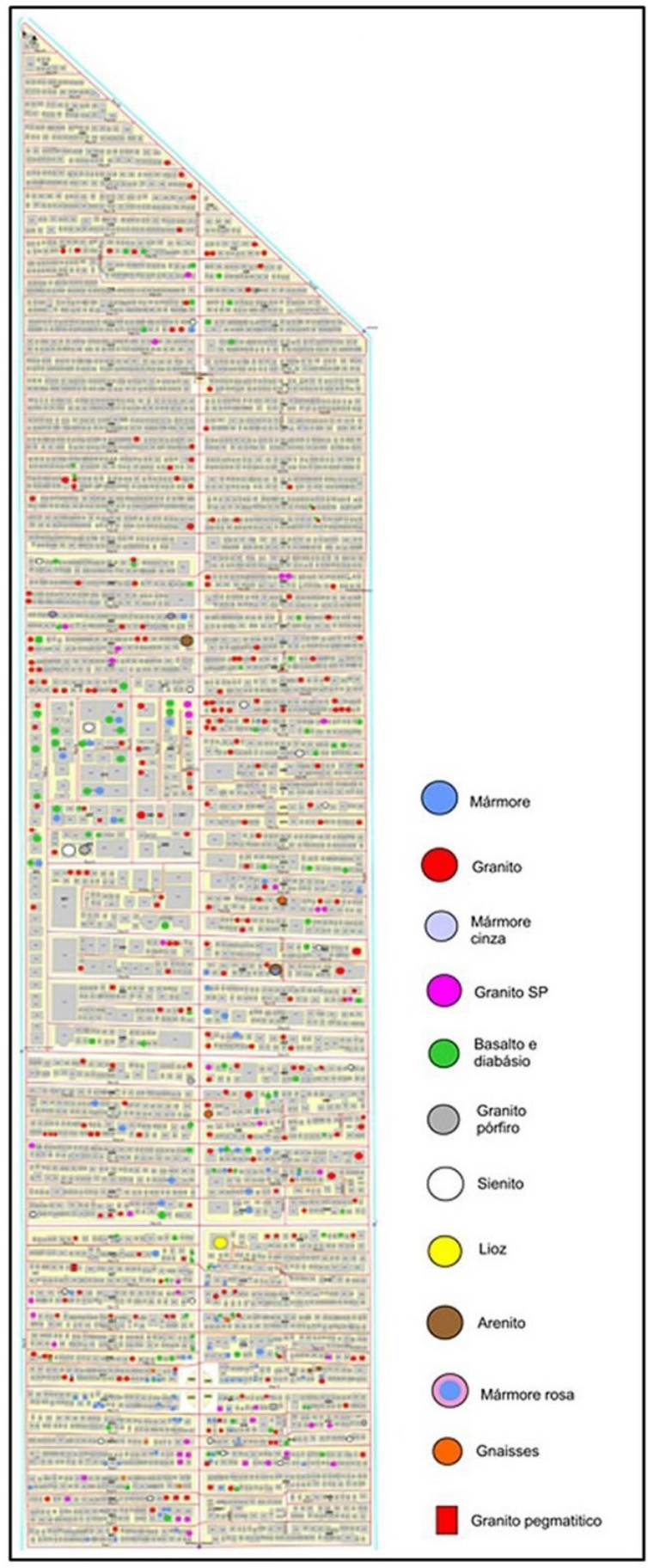

Figura 5 - Mapeamento realizado da geodiversidade do cemitério, indicando as principais litologias destacadas no conjunto cultural.

\subsection{Mármores}

São conhecidas comercialmente como mármores todas as variedades de rochas de composição carbonática, ou seja, rochas metamórficas (mármores stricto sensu) ou sedimentares (calcários) compostas quase que $100 \%$ por calcita e/ou dolomita (minerais compostos por $\mathrm{CO}_{3}$ que, em contato com ácidos, liberam $\mathrm{CO}_{2}$ ).
Mármores importados de Carrara, Itália - os mesmos usados nas obras de Michelangelo, durante a Renascença - estão entre as rochas mais frequentes em esculturas e detalhes de túmulos no cemitério São Francisco de Paula, em Curitiba. São rochas de origem marinha que sofreram metamorfismo há cerca de 30 milhões de anos e formaram os Alpes Apuanos, na região central da Itália (Toscana). Extraído desde o tempo do Império Romano, este mármore se difundiu pelo mundo com a emigração de italianos e transformou-se em sinônimo de qualidade máxima para uso escultural e símbolo da cultura italiana em uso tumular (LICCARDO, 2010). De granulação fina e coloração em geral branca, esta rocha macia apresenta variações cinza e amareladas, algumas vezes com veios acinzentados. Estima-se que $50 \%$ da produção total sejam do mármore branco conhecido como Bianco Carrara que pode ser classificado em cinco categorias em termos de valor - branco puro ou pérola como a mais cara, e a mais barata com tons acinzentados e uma trama de veios escuros com pouca uniformidade (BLASI, 1998). Outros tipos de mármore provenientes de Carrara são o Bianco Venato, quando os veios são uniformes e apresentam qualidade estética, o Arabescato e o Cipollino Zebrato que apresentam desenhos particulares dos veios e o Cremo, variedade de coloração levemente amarelada com ou sem veios aparentes. A variação mais importante e rara $(5 \%$ da produção) é o Bianco Statuario, que apresenta as melhores qualidades para uso artístico - ausência de veios, granulação sacaroide muito fina e cor branca pura a levemente marfim (BLASI, 1998). Este é o mármore mais desejado até hoje para escultura e arte tumular mais nobre.

Sua obtenção é feita pela extração de blocos com cabos de aço impregnados de abrasivo (hoje se usam micro diamantes sintéticos) que funcionam como serra e o uso de explosivos é bastante limitado nas pedreiras, para que a qualidade do material resultante não seja prejudicada. Os blocos podem, então, ser transportados e trabalhados por artistas e artesãos nos locais de destino. A técnica de trabalho no mármore denomina-se entalhe ou escultura, e por se tratar de uma rocha com dureza relativamente baixa, pode facilmente ser desgastada e polida com suavidade, apresentando maior riqueza de detalhes.

Com diferentes histórias e estilos artísticos, a presença desta rocha revela um momento cultural específico do Paraná com a chegada de imigrantes artesãos e quando a qualidade de suas obras em arte tumular passou a representar elegância, status, estilo e pureza, mesmo nos momentos difíceis do descanso eterno (Figura 6). Não obstante sua beleza 
e qualidade no acabamento, o mármore é uma das rochas mais sensíveis ao intemperismo e, principalmente, ao contato com ácidos. Na Europa industrializada o fenômeno das chuvas ácidas e do ataque químico em função da poluição urbana tem resultado na perda inestimável de inúmeras obras de mármore expostas ao tempo. Inicialmente com a perda do brilho de polimento, as esculturas se "dissolvem" literalmente, perdendo detalhes em rostos e mãos, até que estejam totalmente desfiguradas e irreconhecíveis. A manutenção inadequada, com o uso de ácidos e produtos de limpeza, pode acelerar este processo mais ainda, como já se constatou em túmulos e obras no cemitério municipal, que já apresentam sinais deste desgaste químico acelerado.

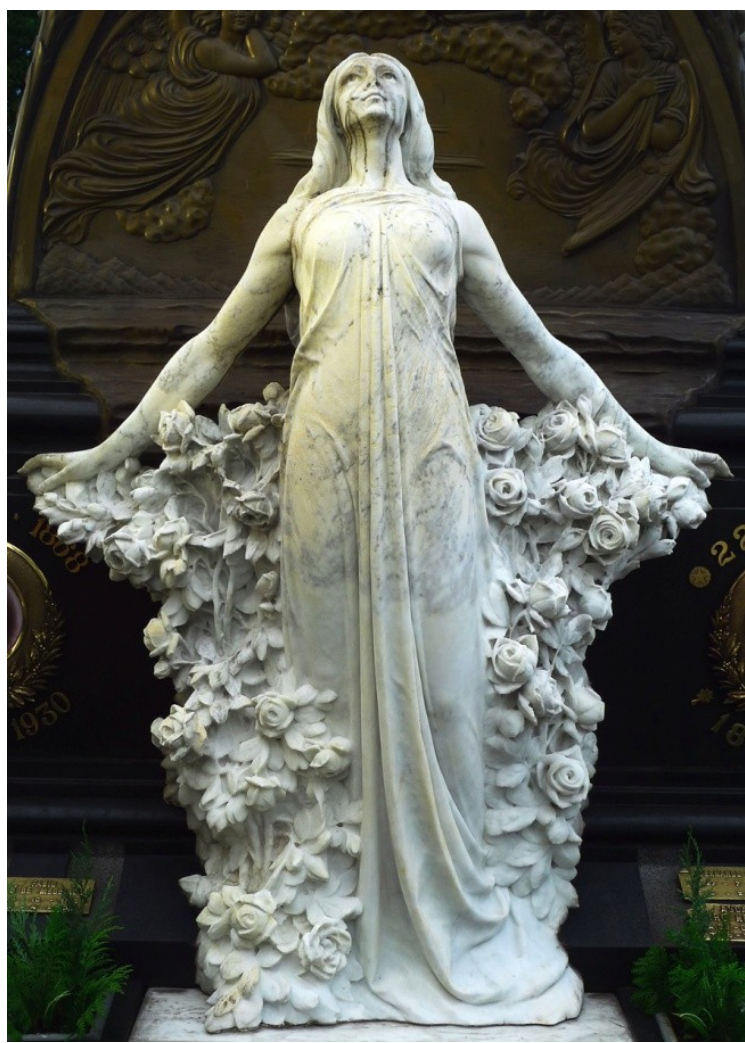

Figura 6 - Exemplo de escultura de elevado refinamento artístico em mármore de Carrara, realizada em Curitiba, na década de 1960.

Além do mármore de Carrara, que responde pela maioria das principais obras do cemitério principalmente no entorno da pracinha central -, alguns poucos mármores regionais estão presentes, como no túmulo do Barão do Serro Azul, esculpido em rocha de tom acinzentado e veios evidentes, característico do Primeiro Planalto Paranaense (região ao norte e noroeste de Curitiba - Figura 7). Estes mármores são geologicamente bem mais antigos (formaram-se há mais de 1 bilhão de anos) e apresentam maior dificuldade de aproveitamento devido à presença de impurezas ou à falta de homogeneidade da rocha. Em túmulos mais recentes (últimos 20 anos) os mármores se apresentam em chapas de revestimento com cerca de 2 centímetros de espessura e podem provir de outros locais como Espírito Santo, Minas Gerais ou outros países, sendo muito rara sua utilização até os anos 1980, no entanto.

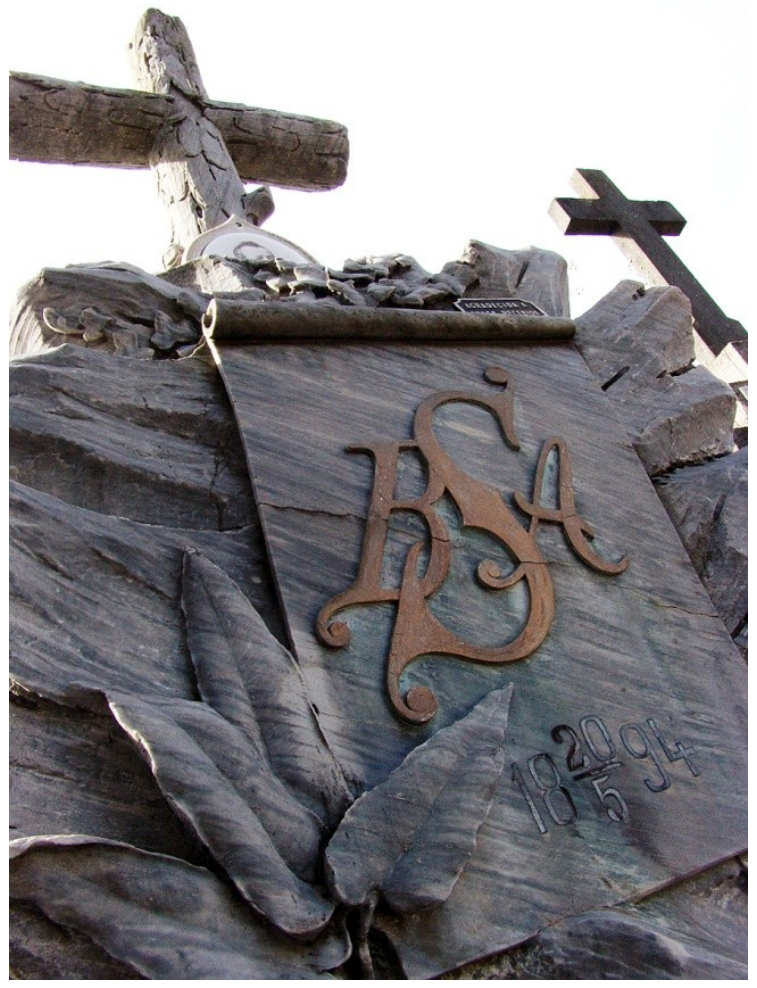

Figura 7 - Mármore cinza do Paraná utilizado no túmulo do Barão do Serro Azul, hoje considerado uma das maiores figuras na história do Estado, morto durante a Revolução Federalista.

Uma obra excepcional no cemitério São Francisco de Paula é o mausoléu da família Tobias de Macedo, elaborado em lioz pelo mestre canteiro português Joaquim M. Silva (Figura 8), localizado na esquina da avenida principal com a Rua 22 (da primeira entrada lateral leste). O lioz é um calcário, de origem marinha, encontrado em Portugal, muitas vezes com presença de fósseis de conchas, o que resulta em texturas e desenhos diferenciados na rocha (SILVA, 2007). Esta material vinha para o Brasil originalmente como lastro de navios desde o século $\mathrm{XVI}$ e foi muito usado em igrejas e fortalezas do período colonial, principalmente nas primeiras cidades da costa brasileira. Este jazigo de lioz foi totalmente entalhado e projetado na região do Porto e montado em Curitiba, destacando-se com extrema singularidade do conjunto geral e é, provavelmente, o único exemplo do gênero em toda cidade. 


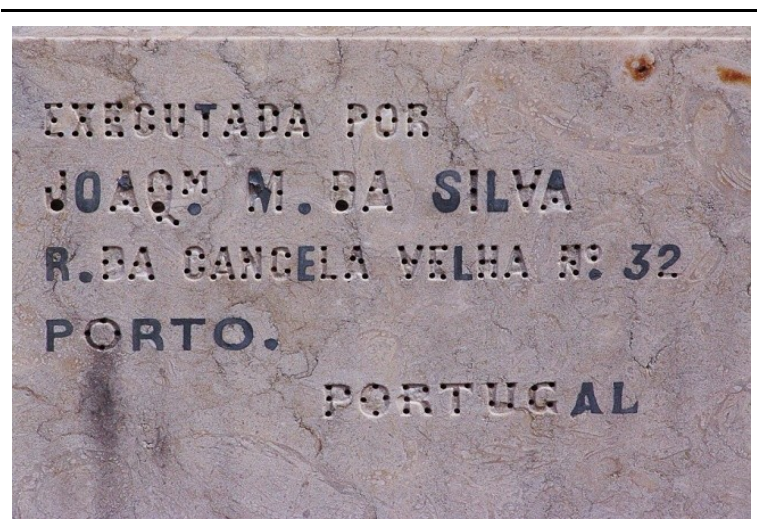

Figura 8 - Inscrição encontrada no mausoléu construído em lioz, que é a única construção neste material conhecida em Curitiba.

\subsection{Granitos}

Rochas mais duras e resistentes, os granitos estão muito presentes em praticamente toda a extensão do cemitério. Granitos são rochas de origem ígnea, formadas em grande profundidade e que possuem em sua composição quartzo e feldspato - os mais abundantes minerais da crosta terrestre - além de alguns minerais escuros e outros em quantidades menores. A presença de quartzo garante a este material uma dureza alta, que dificulta bastante o seu entalhe e resulta em acabamento mais rústico, normalmente. São rochas relativamente abundantes no Brasil e no Paraná provêm, em sua maioria, de pedreiras próximas à Serra do Mar.

A maior parte das cantarias encontradas em túmulos neste cemitério foi realizada com o chamado Granito Rosa Curitiba, material bastante homogêneo de granulação média e tons que vão do cinza ao rosado (Figura 9). É o mesmo granito das calçadas de lousa que revestem os passeios de Curitiba e seu uso na cidade teve início com a ferrovia Paranaguá-Curitiba, já que começou a ser trazido por trem do distrito de Borda do Campo, atualmente município de Quatro Barras, somente em fins do século XIX (LICCARDO et al. 2008).

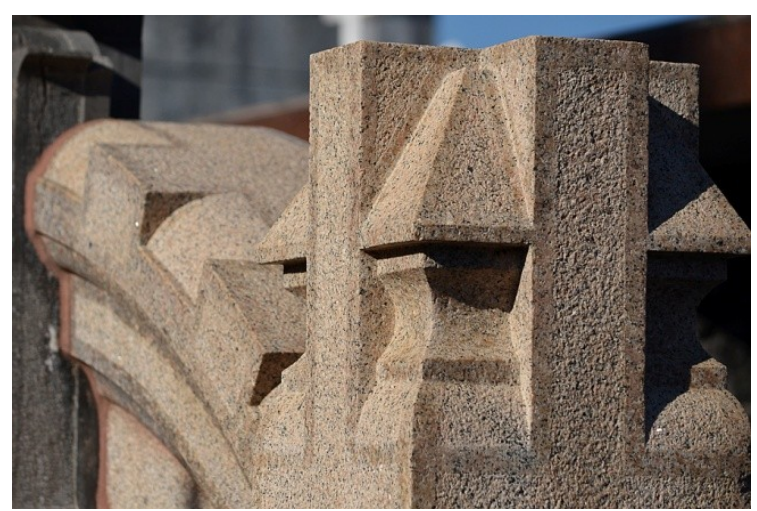

Figura 9-O granito Rosa Curitiba, procedente de Quatro Barras, é a rocha mais abundante no cemitério e é a mesma que reveste a maior parte das calçadas da capital. Detalhe do túmulo de Claudino dos Santos, de influência positivista.
A primeira metade do século $X X$ apresentou um verdadeiro florescimento da técnica de cantaria e sua aplicação na arte tumular. São inúmeros os trabalhos de grande qualidade, com diferentes acabamentos (apicoados, polidos, mistos...), encontrados ao longo do cemitério, principalmente em túmulos construídos nesta época. Nesta técnica o material é trabalhado manualmente com maceta, cinzel e ponteiros e as peças apresentam enorme resistência mecânica, assim como incomparável resistência ao intemperismo e ataques químicos diferentemente do mármore. Exemplo de trabalho excepcional de cantaria feita com o Granito Curitiba é o túmulo de Claudino dos Santos, de influência positivista.

Também destas décadas são encontrados granitos procedentes de São Paulo, seja porque foram elaborados por empresas e artesãos paulistas, seja porque empresas curitibanas passaram a buscar estas rochas em outros estados. São relativamente presentes os granitos conhecidos como Vermelho Bragança e Vermelho Capão, de tons bem mais intensos que o Rosa Curitiba, e o Cinza Mauá, que apresenta cristais maiores de feldspato branco (pórfiros) em meio ao conjunto homogêneo cinza. Deste último os túmulos são revestidos com chapas polidas e não construídos em cantaria como aqueles em Granito Rosa Curitiba. Outra obra que apresenta um granito singular encontra-se na Rua 18, lote 34 . Trata-se de um granito pegmatítico laranja, possivelmente originário de Minas Gerais em placas revestindo o túmulo. Esta rocha tem como característica o tamanho grande dos minerais e originalmente está associada com a gênese de pedras preciosas nos garimpos mineiros. Os cristais de feldspato apresentam até cinco centímetros e proporcionam a beleza da rocha.

\subsection{Rochas negras}

As rochas de cor escura tiveram importante papel na estética do luto em cemitérios ao redor do mundo. No cemitério de Curitiba sua presença é abundante, inclusive nas lousas que compõem os pavimentos mais antigos das ruas. A maior parte das obras foi elaborada com o diabásio, rocha subvulcânica semelhante ao basalto composta por minerais escuros (anfibólios e piroxênios) e algumas vezes com minerais brancos visíveis (feldspatos), muito presente no Primeiro e Segundo Planaltos Paranaenses, inclusive na área urbana de Curitiba. Este material, com idade em torno de 130 milhões de anos, apresenta ótimas características para a cantaria, por ser homogêneo e muito resistente fisicamente, sem a presença de quartzo o que o torna menos duro que o granito (LICCARDO, 2010). Entretanto é comum se verificar pequenos furos na sua superfície após algumas décadas exposto às intempéries, possivelmente associados à alteração 
química de alguns piroxênios. São vários os belos exemplos de obras de diabásio em lápides e tampos no cemitério, assim como nos detalhes com diferentes acabamentos, pois polido este material é preto e quando apicoado (acabamento rústico) adquire um tom mais acinzentado, permitindo interessantes composições (Figura 10). Mais recentemente, a maior parte dos túmulos de diabásio polido vem recebendo um tratamento com betume para maior impermeabilização e para aprofundar os tons escuros.

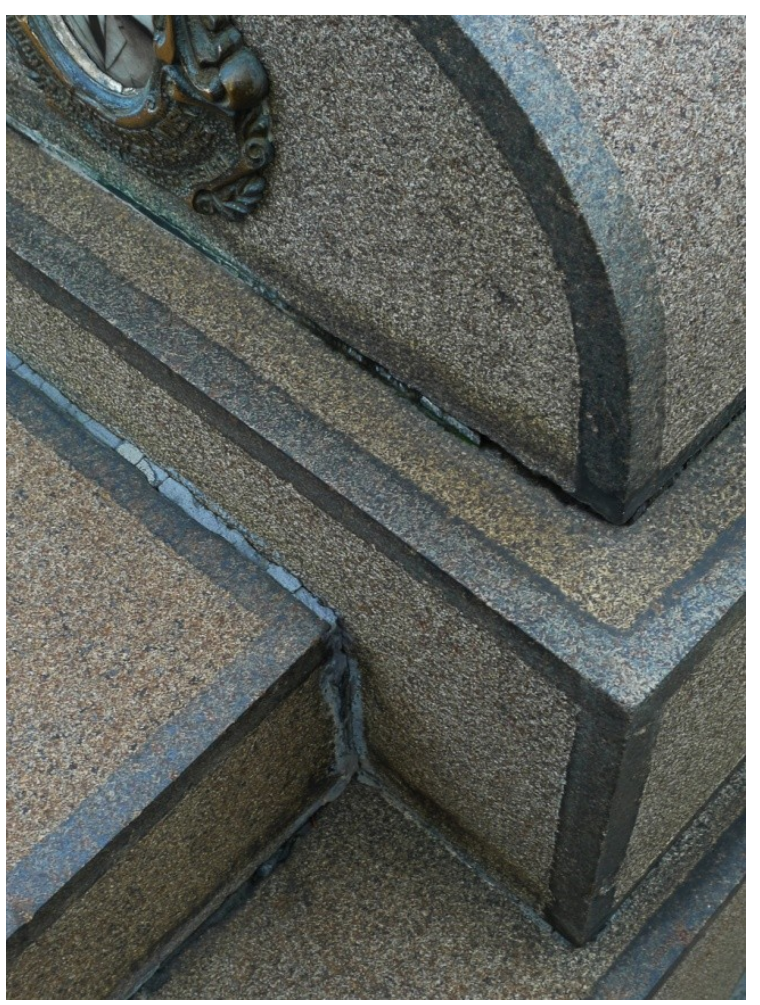

Figura 10 - A única rocha encontrada nos limites da antiga Curitiba que se prestava para o uso em cantaria é o diabásio, muito frequente em túmulos mais antigos, como este com acabamento polido e apicoado.

Em túmulos mais novos ou em lápides elaboradas em outros estados encontram-se alguns exemplos do que se costuma denominar "granito negro" (expressão errônea já que por definição granitos devem ser claros). Trata-se de gabro polido ou outras rochas tingidas com resina preta. Gabro é uma rocha ígnea escura com minerais visíveis formada em grande profundidade e possui a mesma composição do diabásio (também chamado de microgabro). São raros no Paraná e as poucas obras encontradas neste material apresentam-se como placas de revestimento polidas e não cantaria em blocos maciços. Uma rocha escura famosa e muito utilizada em vários cemitérios do Brasil é o Preto Piracaia (um monzonito na realidade) que apresenta cristais de feldspato dispersos que se assemelham a flocos de neve.

\subsection{Outras rochas}

Numa evolução histórica, vários túmulos construídos ou reformados a partir dos anos 1970 começaram a receber o revestimento de placas de rochas das mais variadas procedências, fruto da oferta destes materiais num mercado globalizado. Ao mesmo tempo em que os granitos e mármores apresentam maior opção de escolha, as rochas são vendidas somente em chapas praticamente, e obras em cantaria caíram em desuso.

É notável a presença de rochas como o sienito revestindo alguns túmulos e mausoléus. O sienito é uma rocha ígnea formada em profundidade, semelhante ao granito, mas sem a presença de quartzo. Apresenta-se em tons cinza esverdeados e é conhecido como Verde Tunas, produzido somente em Tunas, no Paraná, sendo exportado para vários países.

A presença de arenitos - rochas sedimentares formadas pela litificação de areias - também chama a atenção em dois túmulos. Um deles, revestindo um mausoléu em blocos pequenos na esquina da avenida principal com a Rua 30, é um arenito avermelhado com faixas amarelas proveniente de São Paulo. Este arenito, com cerca de 140 milhões de anos, em seu local de origem constitui um grande reservatório de água subterrânea que é conhecido como Aquífero Guarani. A outra obra de arenito é um túmulo na Rua 35 , quadra 58 , lote 10 , que provavelmente foi elaborado na cidade da Lapa, fonte deste tipo de rocha e que tinha tradição de obras em cantaria. Construído na primeira metade do século 20 este túmulo apresenta os tampos trabalhados em mármore de Carrara, o que torna o conjunto bastante particular.

Finalmente, uma rocha metamórfica comum, o gnaisse, tem sido usada tanto como blocos pequenos ou chapas de revestimento com bastante frequência nos últimos anos. Gnaisses são rochas acinzentadas com faixas claras e escuras, comuns em Curitiba, mas que provêm de vários locais do Brasil como material de revestimento, sendo um dos mais baratos. Seu uso mais comum é o revestimento de muros e no cemitério tem sido usado nas reformas recentes em alguns túmulos

\section{RESULTADOS E DISCUSSÃO}

O levantamento dos tipos litológicos presentes no Cemitério São Francisco de Paula trouxe à tona uma importante informação quanto à predominância no uso de certas rochas ao longo da história do município. A utilização de diabásio em lápides e cantarias é característica dos primórdios do cemitério, por ser o material de fonte mais próxima apto para este uso. As primeiras pedreiras 
localizavam-se dentro do que hoje é o centro de Curitiba. Também houve o uso intenso por volta dos anos 1940, por questões de moda e uma associação estética das rochas negras com o sentimento de luto. Em boa parte das calçadas que pavimentam as ruas do cemitério (e da cidade) foram utilizadas de lousas de diabásio.

Com a chegada da ferrovia, Curitiba passou a receber o granito proveniente dos contrafortes da Serra do Mar (Borda do Campo), no início do século XX. Toda a cidade recebeu pavimentação com esta rocha na forma de paralelepípedos, lousas e cantarias. Este fato refletiu-se no contexto do cemitério, já que a maior parte das cantarias foi realizada com esta rocha entre 1900 e 1970 e é a mais presente entre os túmulos. Obras de maior refinamento em granito são ligadas ao movimento positivista que apresenta seu auge, no Paraná, nas primeiras décadas do século XX.

A definição das elites e burguesia paranaenses e a presença de imigrantes italianos refletem-se claramente no uso intenso de mármore de Carrara e no refinamento estético da estatuária e da cantaria, que expõe a riqueza e a pompa desde o final do século XIX até meados do século XX.

Este levantamento trouxe à tona a possibilidade de interpretação da informação litológica para um melhor entendimento da história e das sutilezas socioculturais. O conteúdo sobre a geodiversidade e seu uso no meio urbano mistura-se facilmente com outros conteúdos, o que aponta a possibilidade de integração deste segmento no amálgama cultural em análises de patrimônio.

As discussões que envolvem o tombamento de patrimônios culturais - especialmente no que toca a possibilidade do Cemitério São Francisco de Paula vir a ser tombado - não podem prescindir da informação geológica sobre os materiais com que foram construídos. Muito do que foi perdido pelos registros históricos convencionais pode ser resgatado pelo cruzamento de dados provenientes de levantamentos acurados sobre a geodiversidade e o patrimônio geológico construído.

\section{REFERÊNCIAS BIBLIOGRÁFICAS}

Ariès, P. 2003. História da morte no ocidente. Rio de Janeiro: Ediouro. 312p.

Bellomo, H. R. 2000. Cemitérios do Rio Grande do Sul; Arte, Sociedade, Ideologia. Porto Alegre, Ed. da PUCRS. 272p.

Blasi, P. 1998. Le varietá Merceologiche dei Marmi Carraresi Carrara, Eurominerals and Society of Mining Profesors. Itália. $22 \mathrm{p}$.

Catroga, F. 1999. O céu da memória: Cemitério Romântico e Culto Cívico dos Mortos em Portugal (1756-1911). Coimbra: Livraria Minerva Editora. 352p.

Carollo, C. L. L. 1995. Cemitério Municipal São Francisco de Paula: monumento e documento. Curitiba: Boletim Informativo da Casa Romário Martins, Fundação Cultural de Curitiba. V.22.

Costa, F. R. 2009. Turismo e patrimônio cultural: interpretação e qualificação. São Paulo: Editora Senac. São Paulo. 251p.

Grassi, C. 2006. Um olhar... A arte no silêncio. Curitiba: Clarissa Grassi, 2006.

Imaguirre, K. 1995. Boletim Informativo da Casa Romário Martins. Cemitério Municipal São Francisco de Paula: monumento e documento. Curitiba: Fundação Cultural de Curitiba, Volume XXI. Número 104

Liccardo, A. 2010. La pietra e L'uomo - Cantaria e Entalhe em Curitiba. São Paulo, Ed. Beca-Ball. 156p.

Liccardo, A.; Mantesso-Neto, V.; Piekarz, G. F. 2012. Geoturismo Urbano - Educação e Cultura. Anuário do Instituto de Geociências - UFRJ. Rio de Janeiro V. 35 p. 133-141.

Liccardo A.; Piekarz, G. F.; Salamuni, E. 2008. Geoturismo em Curitiba. Curitiba, Mineropar.122p.

Motta, A. 2008. A flor da pedra: formas tumulares e processo sociais nos cemitérios brasileiros. Recife: Fundação Joaquim Nabuco, Ed. Massangana. 202p.

Oliveira, C. A. P. 2011. Educação Patrimonial no IPHAN. Dissertação (Mestrado) - Departamento de Diretoria de Formação Profissional, Escola Nacional de Administração Pública, Brasília. 131p.

Poulot, D. 2009. Uma história do patrimônio no Ocidente, séculos XVIII-XXI: do monumento aos valores. São Paulo: Estação Liberdade. 239p.

Queiroz, F. 2005. Os cemitérios históricos e o seu potencial turístico em Portugal. [s. L.]: Congresso "Repensar As Cidades - Novos Tempos Para As Velhas Cidades", 2005. Disponível em: $\quad$ http://21gramas.pt/Uploads/17480711200709.pdf. Acesso em: 01 ago.2012.

Silva, Z. C. 2007. O Lioz Português - De lastro de navio a arte na Bahia. Rio de Janeiro. Versal Editores. 156p.

Vovelle, M. 2004. Ideologias e Mentalidades. São Paulo, Brasiliense. 267p.

Contribuição ao II Simpósio Brasileiro de Patrimônio Geológico

I Workshop Brasileiro de Patrimônio Geológico Construído

24 a 28 de setembro de 2013, Ouro Preto, MG 